\title{
Performance Assessment of Multi-Electrodes Reactors for Scaling-up Microbial Fuel Cells
}

\author{
Mariagiovanna Minutillo ${ }^{1}$,Rosa Anna Nastro ${ }^{2}$, Simona Di Micco ${ }^{1,{ }^{*}}$, Elio Jannelli ${ }^{1}$, Raffaele \\ Cioffi ${ }^{1}$,Maria Di Giuseppe ${ }^{2}$
}

${ }^{1}$ University of Naples "Parthenope", Naples, Italy

${ }^{2}$ Sudgest scarl, Naples, Italy

\begin{abstract}
The microbial fuel cells (MFCs) represent an emerging technology for converting directly organic waste into electricity. In recent years, the application of MFCs to the energy recovery from wastes has been widely explored. The main aspect that limits the development and implementation of this technology on a larger-scale is the possibility of realizing its scaling-up. In order to overcome this critical factor, it is useful to analyze novel MFCs configurations based on compact reactors with multiple electrodes.In this paper, single chamber MFCs provided with multiple fiber brush anodes and a single air-cathode were designed and realized by using a $3 \mathrm{D}$ printer. The reactors had a cubic shape, with a cylindrical chamber of $350 \mathrm{~mL}$ in volume. The mineral medium added with sodium acetate $(0.25 \mathrm{M})$, as sole source of carbon and energy to sustain exoelectrogenic bacteria metabolism, were used. Anodes biofilms were prepared from a mix of compost and sodium acetate dissolved in phosphate buffer solution $(0.2 \mathrm{M})$, in a 1:3 ratio. The performances of two MFCs provided with two and three anodes were assessed in terms of voltage, current density and power density. These performances were compared to those of a smaller cubic MFC (30mL).
\end{abstract}

\section{Introduction}

The scaling-up of microbial fuel cells (MFCs) requires the development of optimized reactor configurations in which the electrodes are properly spaced [1]. As a matter of fact, one of the significant factors affecting the performances of MFCs is the spacing between the anode and the cathode. The electrodes spacing influences the internal resistance that depends also on the electrodes materials and the mass transport issues. The decrease of the electrodes spacing can reduce the internal resistance (the ohmic losses) and, as a consequence, increase the power production. On the other hand, it is necessary to do not reduce excessively this distance in membrane-less reactor, since it might interfere negatively on the electrochemical processes occurring at the electrodes, if these last ones are placed too close to each other.

Thus, the approach followed in the scaling-up of MFCs is the development of reactors with larger chambers provided with more electrodes (generally anodes): multi-electrodes configurations.

Yongtae Ahn \& Bruce E. Logan [2] analyzed the behaviors and performances of MFCs with multiple anodes and with separator electrode assemblies (for minimizing electrode spacing) under both fed-batch and continuous flow operations. The reactors contained three anodes consisting of carbon fibers brushes (25-mm diameter by $35-\mathrm{mm}$ length) and a single cathode with a surface of $35 \mathrm{~cm} 2$ exposed to air. In fed-batch operation the maximum measured power density was $975 \mathrm{~mW} / \mathrm{m} 2$, while in the continuous flow operation the maximum power density

* Corresponding author: simona.dimicco@uniparthenope.it 
results $880 \mathrm{~mW} / \mathrm{m}^{2}$. Lanas et al. [3], studied a larger scale MFCs configurations based on multiple anodes that differed for the anode-brush diameter, for the number of anodes and for the electrodes spacing. Their analysis was performed for MFCs operated in fed-batch and continuous flow mode. Results highlighted that, in the fed-batch, the using of fewer but larger anodes (i.e. 3 anodes with $25 \mathrm{~mm}$ diameter) with a small space between the brush edge and the cathode, allowed to achieve better performance with respect to the using of more anodes but smaller (i.e. 8 anodes with $8 \mathrm{~mm})$ with a bigger electrodes space $(1240 \mathrm{~mW} / \mathrm{m} 2 \mathrm{vs} .690$ $\mathrm{mW} / \mathrm{m} 2$ ). The same result was obtained in continuous flow operation, although the measured power densities were lower. Moreover, Lanas et. al [3] demonstrated that by moving the center of the smaller brushes closer to the cathode, the power increased in both feeding modes, so that the multi-electrode MFCs configurations could be optimized by selecting smaller anodes, but by placing them as close as possible to the cathode.

In this study, the design, the development and the performance analysis of larger scale multielectrodes MFCs have been carried out in order to investigate on the potentiality of these configurations to realize the scaling-up. Moreover, the comparison with a smaller singleanode reactor was performed for estimating the influence of geometric parameters on the performances.

\section{Materials and Methods}

\subsection{Larger-scale multi-anodes MFCs: reactors design and development}

In order to assure the optimal conditions for the power production, the design of largerscale microbial fuel cells (MFCs) requires a detailed analysis on the reactor configuration, on the choice of bio-compatible and cheap materials and on the electrodes spacing.

In this study, single-chamber and air-cathode reactors with a different number of the anodes (two and three) have been designed and developed.

The reactors are realized by using the Poly-Lactic Acid (PLA)-based material, that is a solution not toxic for microorganisms, completely recyclable and, thus, it contributes to the sustainability of this technology. FDM (Fused Deposition Modeling) printer (Delta Wasp 2040 , Italy) has been used to fabricate the reactors, once the geometry was defined. The 3D printing is realized by means of a mobile nozzle with a hot end that melts the material while setting it down on a flat plate, so that the construction process is obtained by adding thin layers one by one [4]. This additive process ensures that no waste is produced and very complex shapes with high precision $(5 \mu \mathrm{m})$ can be obtained in a short time. The 3D printer requires a GCODE file as input that is generated by using the open source software CURA (Ultimaker, USA), which can be considered a computer-aided production software (CAM). This software cuts the imported geometry into slices and generates commands for most commercially available 3D printers. Fig.1 shows the reactor, used for the experiments, designed trough Solid Works $\complement$. 


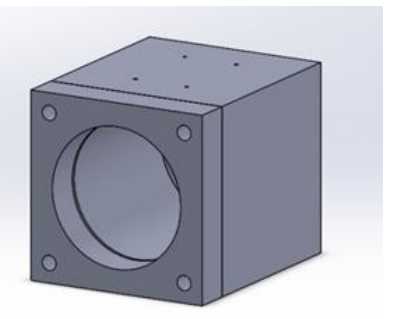

Fig.1. Design of the larger scale MFC reactor.

The anode material has a great influence on adhesion and proliferation of bacteria and on biofilm growth and, as a consequence, on the power generation [5]. The cathode material affects the MFC performance, since on its surface the reduction reaction, involving oxygen (or other electronic acceptor), electrons and protons, occurs. For these reasons, the choice of the electrodes should meet the following characteristics: high conductivity, large surface area, high porosity, good biocompatibility and low costs. Carbon-based materials generally represent the best solution.

Thus, a carbon fiber brush has been used as the anodic electrode and an activated carbon coated with PTFE (polytetrafluoroethylene) layer and with a nickel mesh (as current collector) is used as cathodic electrode. Fig. 2 shows the selected electrodes.

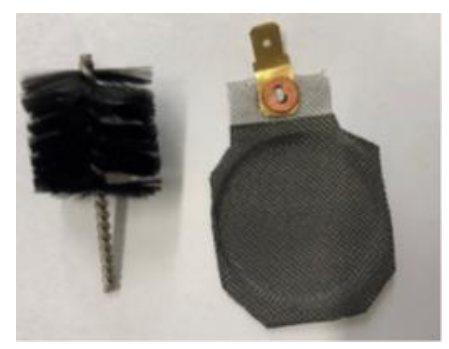

Fig.2. The anode and the cathode used in the MFCs

The anode size is $25 \mathrm{~mm}$ in diameter and $50 \mathrm{~mm}$ in length and each carbon fiber has a diameter of $7.2 \mu \mathrm{m}$ (a total specific surface of $0.22 \mathrm{~m}^{2}$ ); the fibers are fixed on a titanium wires (made by Mill-Rose) [6]. The developed reactors of the larger-scale multi-electrodes MFCs are illustrated in Fig. 3.

Moreover, the main geometric details are illustrated in table 1. 


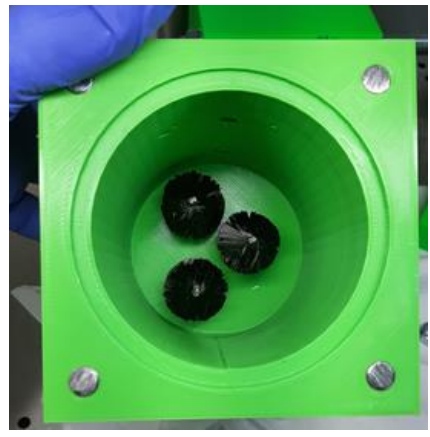

a)

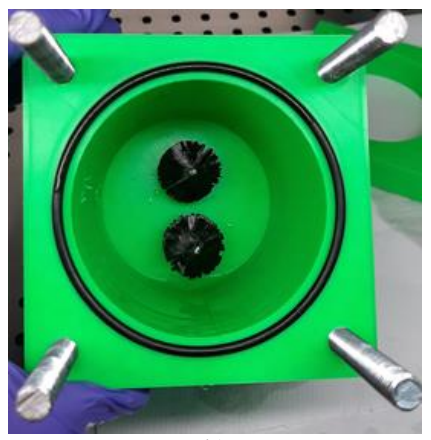

b)

Fig.3. Multi-electrode cells with 3 anodes (a) and 2 anodes (b)

Table 1. Geometric data of Multi-electrodes MFCs

\begin{tabular}{|l|c|c|}
\hline Geometric details & Units & Values \\
\hline External edge & $\mathrm{cm}$ & 9 \\
\hline Diameter of the internal cylindrical chamber & $\mathrm{cm}$ & 7 \\
\hline Total internal volume & $\mathrm{ml}$ & 350 \\
\hline Cathode surface & $\mathrm{cm}^{2}$ & 38.5 \\
\hline
\end{tabular}

As it can be noted, in the first prototype (MFC_3a) 3 anodes are used and in the second one (MFC_2a) 2 anodes are placed inside the volume. The projected area of these brushes relative to the cathode is different $\left(0.38 \mathrm{~cm}^{2} / \mathrm{cm}^{2}\right.$ and $0.25 \mathrm{~cm}^{2} / \mathrm{cm}^{2}$ for the MFC_3a and MFC_2a, respectively). The brushes are placed orthogonally to the cathode and the anodes are connected externally in parallel by a single copper wire. The space between each brush edge and the cathode is $3 \mathrm{~cm}$.

\subsection{Substrate and Inoculum}

The experiments were carried out by using a specific substrate based mineral medium [7], consisting of $4 \mathrm{~g} / \mathrm{L}$ of sodium acetate in $50 \mathrm{mM}$ of PBS $\left(\mathrm{Na}_{2} \mathrm{HPO}_{4}, 4.09 \mathrm{~g} / \mathrm{L}\right.$ and $\mathrm{NaH}_{2} \mathrm{PO}_{4}$ $\left.\mathrm{x} \mathrm{H}_{2} \mathrm{O}, 2.93 \mathrm{~g} / \mathrm{L}\right), \mathrm{NH}_{4} \mathrm{Cl}(0.31 \mathrm{~g} / \mathrm{L})$ and $\mathrm{KCl}(0.13 \mathrm{~g} / \mathrm{L})$, metal salts $(12.5 \mathrm{~mL} / \mathrm{L})$ and vitamin $(5 \mathrm{~mL})$ solutions.

Sodium acetate was chosen because, according to the scientific literature [7], it provides the highest energy yield to sustain exo-electrogenic bacteria metabolism if compared with fermentable compounds like glucose, lactose, starch and sucrose. The use of a mineral medium with a fixed formulation, led to the elimination of variables related to fuel composition, so that the performance comparison between the tested cells is mainly due to their configuration and management.

The choice of the inoculum fell on the bacteria from compost that appear to be a good source of exo-electrogenic bacteria, like Bacillus, Geobacillus and Brevibacillus, that favour the oxidation reaction on the anode [8]. Furthermore, there is evidence of a potential long-term utilization as a source of energy for MFCs [9] [10].

In order to optimize the interaction between anodes and bacteria, the anodes were pretreated by soaking them into $0.5 \mathrm{M}$ hydrochloric acid for 3 hours and, then, rinsing them for 5 times with distilled water as suggest in ref [7]. Then, the anodes were incubated for 30 days at 30 ${ }^{\circ} \mathrm{C}$, in a mixture consisting of compost, distilled water, sodium acetate $(0.4 \% \mathrm{w} / \mathrm{v})$ and Phosphate Buffer Solution (50 mM). 


\subsection{MFCs testing procedure}

The two MFCs prototypes were tested in different operating conditions. Before starting the testing activity, the cells were put in the OCV (Open Circuit Voltage) condition for 24 hours and, subsequently, they were connected to an external resistance of $1000 \mathrm{Ohm}$ for other 24 hours. The operation for $24 \mathrm{~h}$ in OCV condition was needed for allowing to bacteria the storing of the metabolic energy that will be converted into electricity.

The third step was to keep the cells for further 6 hours in the OCV condition. At the end of this acclimation period the polarization curve was measured by varying the external resistance in the range $1 \mathrm{M} \Omega-500 \Omega$.

Thus, the external resistance, at which the maximum power density was achieved, was applied for 24 hours. During the application of this external load, a voltage reversal was observed in MFC_3a. Thus, it was decided to put again both multi-electrode MFCs in the OCV condition, changing the fuel every three days until a proper stabilization was reached (positive voltage at closed circuit, absence of multiple peaks and of overshoots in the polarization curves).

For the data acquisitions Arduino Mega evaluation boards were used. The fixed signal sampling frequency was 1 minute. A Lab View interface was used to record all data.

Because it is useful to evaluate the readiness of the cells in the electric power production under variable voltage conditions, 3 testing cycles were carried out for characterizing the cells behaviors under different procedures. Details on these cycles are reported as follows:

- $\quad$ Cycle $\mathrm{C} 1$ = step 1: operation without load for $6 \mathrm{~h}$ (OCV condition); step 2: polarization curve operation; step 3: operation at fixed power for $24 \mathrm{~h}$ (at the maximum power measured at the step 1);

- $\quad$ Cycle C2 = step 1: operation without load for $5 \mathrm{~h}$ (OCV condition); step 2: polarization curve operation; step 3: operation at fixed power for $12 \mathrm{~h}$ (at the maximum power measured at the step 1);

- $\quad$ Cycle C3 = step 1: operation without load for 2 minutes (OCV condition); step 2: polarization curve operation; step 3: operation at fixed power for $6 \mathrm{~h}$ (at the maximum power measured at the step 1);

In the first testing cycle $\mathrm{C} 1$, the MFCs were put in the $\mathrm{OCV}$ condition (at rest) for $6 \mathrm{~h}$ in order to allow a proper storage of metabolic energy for being, subsequently, converted into electricity by bacteria; the following steps were the polarization curve measurement and the operation at constant load by applying the external resistance, at which the maximum power was achieved.[11][12] In the second testing cycle C2, the OCV phase was reduced to 5 hours as well as the time of the operation at maximum power was decreased to 6 hours. The reduction of these phases gave information about the response of the cells under different operating conditions. Finally, the cycle C3 was set-up in order to assess the effect of the absence of OCV phase on MFCs performance and, as a consequence, the ability to continuously produce energy. 


\section{Results and Discussion}

\subsection{Polarization curve measurement}

At the beginning of the experimental activity, the multi-electrode MFCs showed an instability as resulted from the two-peaks and overshoots characterizing the polarization and power density curves during the first two weeks. These results might be addressed to differences in the growth of the biofilm during the acclimation phases. It took some more days to achieve a good stability in their behaviors during the performed tests.

In figure 4 the power density and polarization curves of the MFC_2a and MFC_3a measured at the 6 th, the $9^{\text {th }}$ and $16^{\text {th }}$ week, are illustrated. It is possible to note that, at the $6^{\text {th }}$ week, the MFC_2a showed better performance in terms of power and current density $\left(7.2 \mathrm{~mW} / \mathrm{m}^{2}\right.$ and $12.7 \overline{\mathrm{mA}} / \mathrm{m}^{2}$ ). During the time, its behavior remained stable in terms of electric power production, but at the $13^{\text {th }}$ week its performances overly decreased.

With respect to MFC_3a, it is worth noting that its best performance was obtained at $9^{\text {th }}$ week, reaching a maximum power density of $13.1 \mathrm{~mW} / \mathrm{m}^{2}$ at $33.2 \mathrm{~mA} / \mathrm{m}^{2}$. Thus, the multi-electrode reactor with three anodes showed a better behavior in terms of power density, even if in a longer time. The MFC_2a showed a lower capacity to perform the electrochemical oxidation of the acetate that was overcome by concurrent fermentation processes; this is confirmed by the analysis of the $\mathrm{pH}$ measurements that, for the MFC_2a, was about $8.4 \pm 0.2$ (a higher value, equal to $8.7 \pm 0.2$, was measured in the MFC_3a).

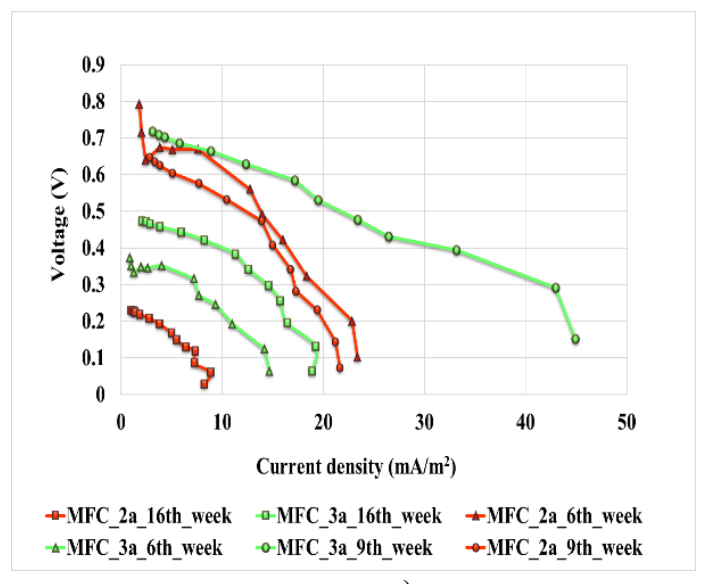

a)

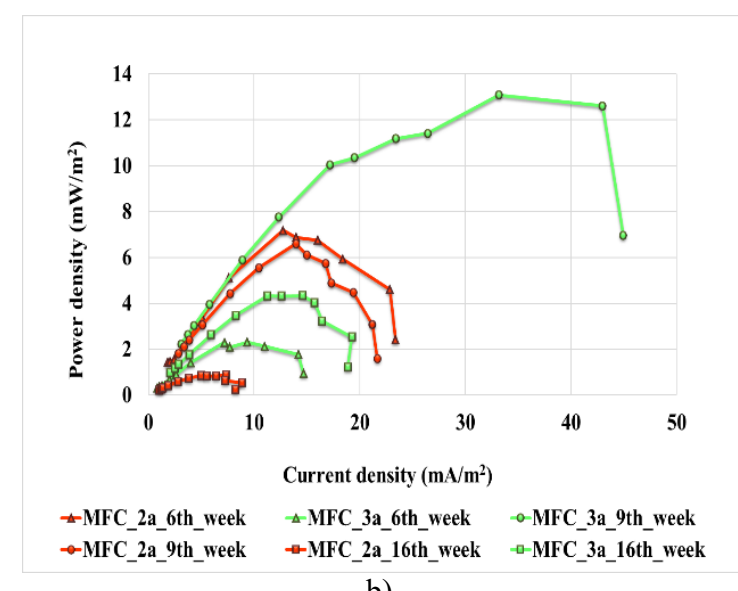

b)

Fig.4. Polarization (a) and power density (b) curves of MFC_2a and MFC3a during the experimental activity 


\subsection{MFCs management cycles}

The behavior and performances of MFC_2a and MFC_3a were also evaluated by applying the testing procedure based on the 3 above mentioned measurement cycles: $\mathrm{C} 1, \mathrm{C} 2$ and $\mathrm{C} 3$.

Figure 5 depicts the current density trends during the Cycle $\mathrm{C} 1$. The resistances, illustrated in the figure, refer to the external resistance at which the cells reached the maximum power density during the external load application.

MFC_3a was able to produce more current during the whole Cycle $\mathrm{C} 1$, but it is possible to note a great variation of these currents in the time. MFC_2a produced less current but the measured values were quite constant in the time and, at the end of the Cycle $\mathrm{C} 1$, this cell assured higher current densities with respect to MFC_3a. This observation confirms that the presence of three anodes accelerates the substrate consumption by bacteria.

Figure 6 illustrates the current density trends during the Cycle C2. During this test, the operation of the cells at maximum power density was reduced form $24 \mathrm{~h}$ (as in the Cycle 1) to $12 \mathrm{~h}$. Similarly, to the results illustrated in Fig. 5, the MFC_3a showed higher values of current density, but this energy production was more variable in the time. Moreover, it is possible to note that the shorter times assigned to the step 2 (operation at fixed power) and step 3 (OCV condition) led, first of all to the reduction and then to the disappearance of the peaks in the current production.

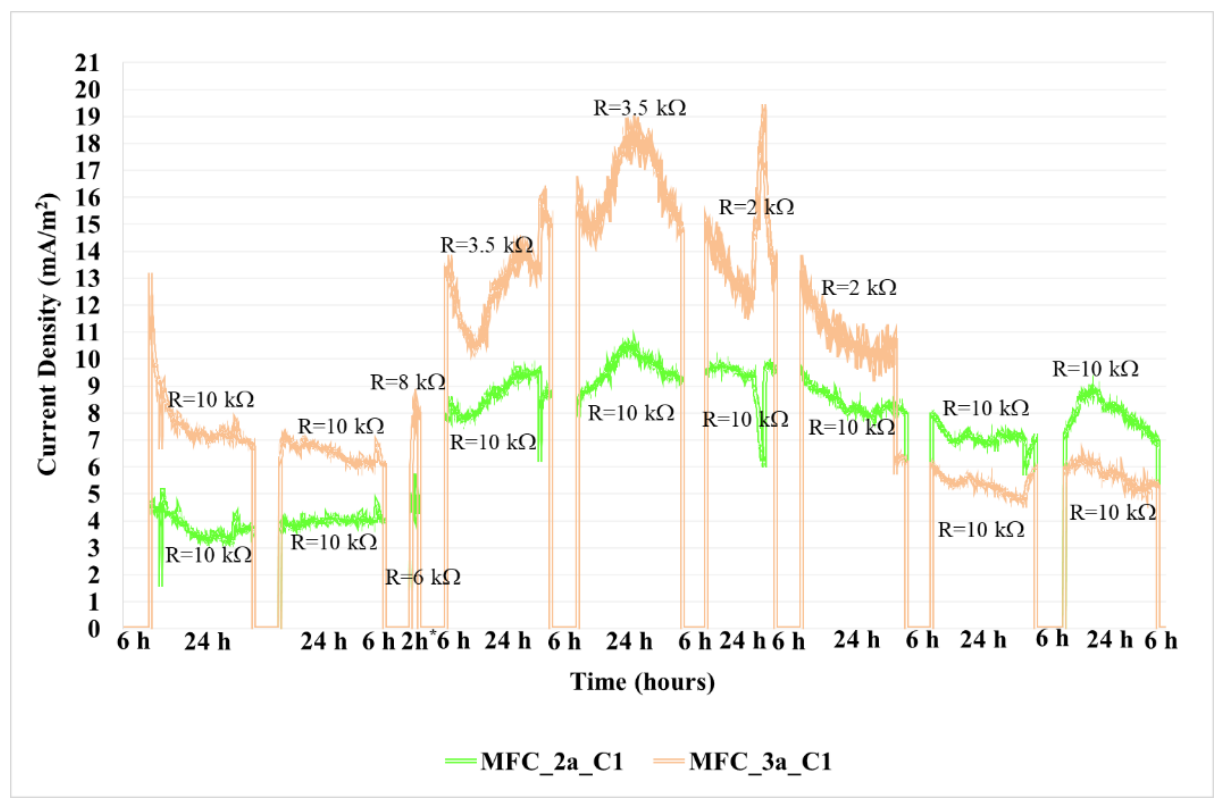

Fig.5.Current density trends during the Cycle $\mathrm{C} 1$ (*failure of the acquisition system) 


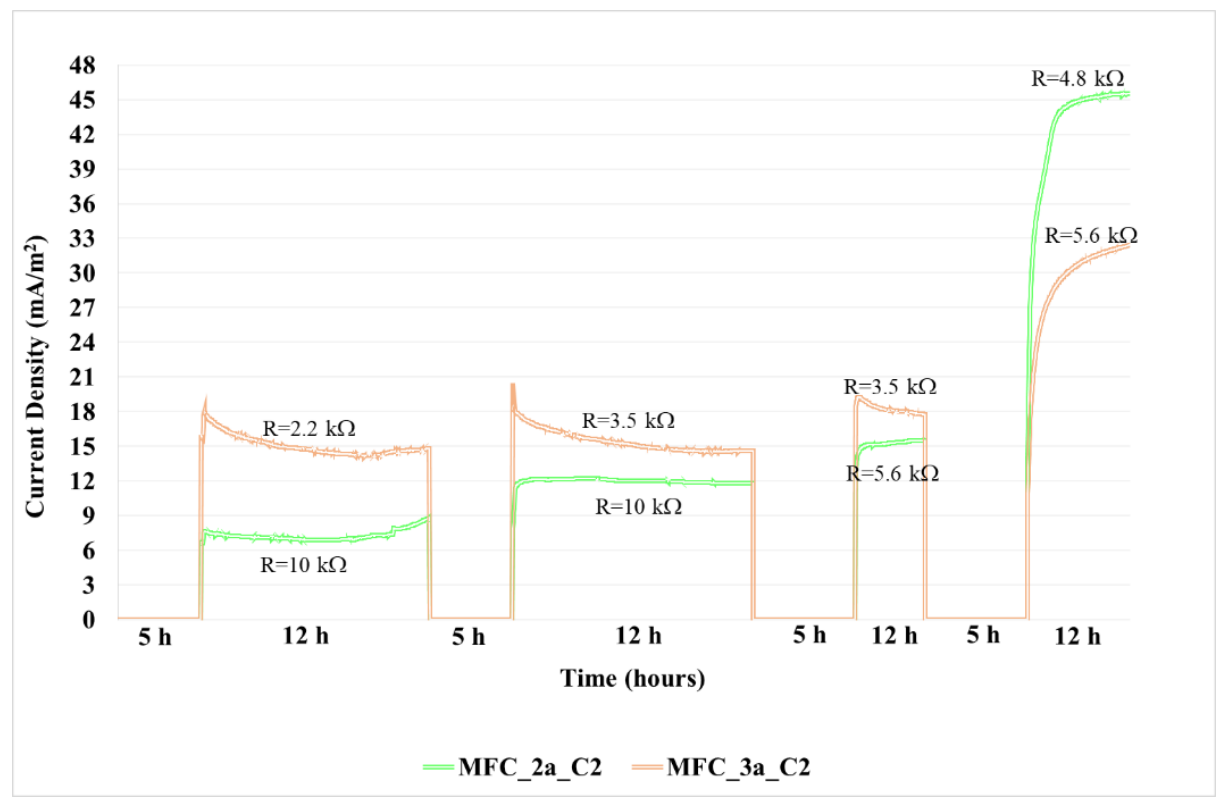

Fig.6. Current density trends during the Cycle C2.

Figure 7 shows the current density trends during the Cycle C3. It is worth noting a downward trend of the curves with respect to the results obtained during the Cycle $\mathrm{C} 1$ and Cycle $\mathrm{C} 2$. The lack of an OCV phase in the Cycle $\mathrm{C} 3$ did not damage the MFCs, whose electrochemical behavior remained unchanged during the polarization experiments.

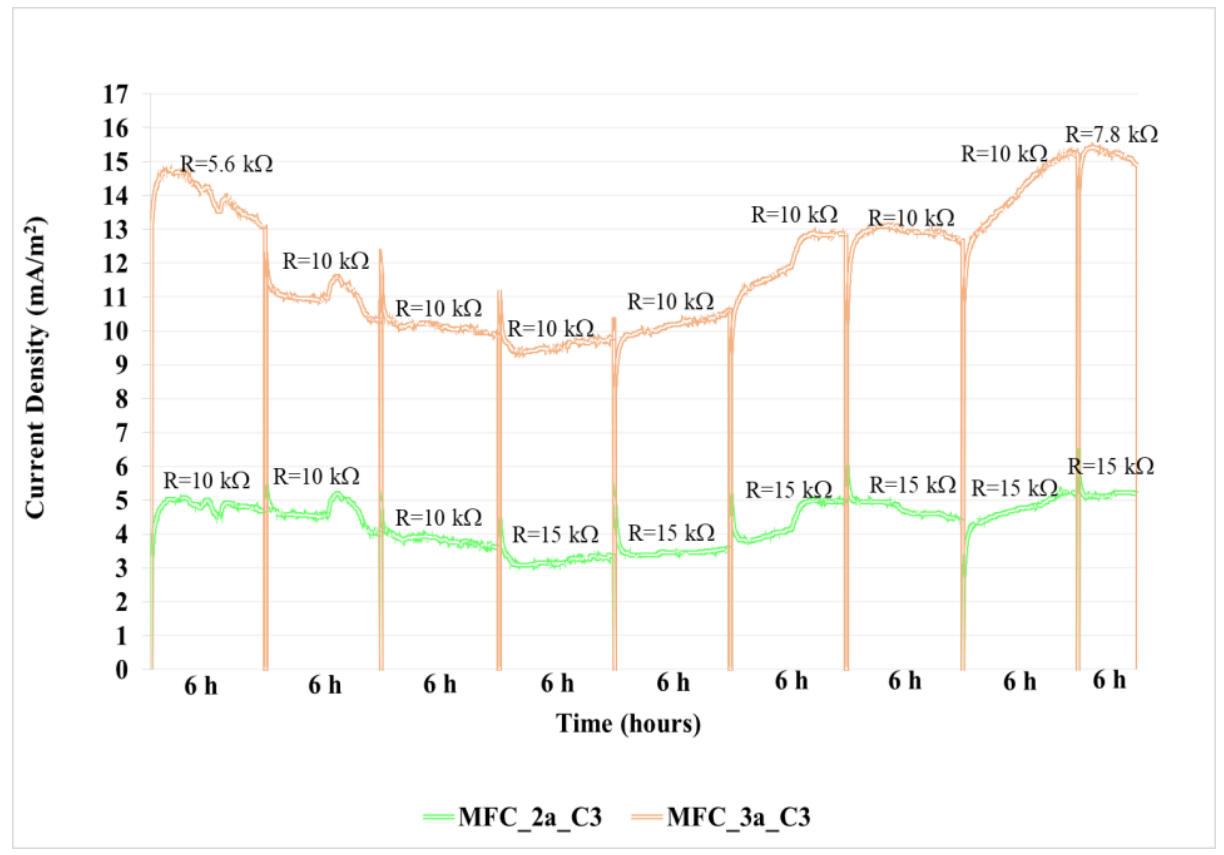

Fig.7. Current density trends during the Cycle C3. 


\subsection{Small scale single-anode MFC: reactors design and development}

The smaller scale single-anode MFC (MFC_a) was realized by using the same technique of the 3D printing used for the multi-electrodes cells. The geometric details are illustrated in table 2. Figure 8 depicts a photo of the reactor and illustrates the performance of the cell.

Table 2. Geometric data of single-anode MFC

\begin{tabular}{|l|c|c|}
\hline Geometric details & Units & Values \\
\hline External edge & $\mathrm{cm}$ & 4 \\
\hline Diameter of the internal cylindrical chamber & $\mathrm{cm}$ & 3 \\
\hline Total internal volume & $\mathrm{ml}$ & 30 \\
\hline Cathode surface & $\mathrm{cm}^{2}$ & 7 \\
\hline
\end{tabular}

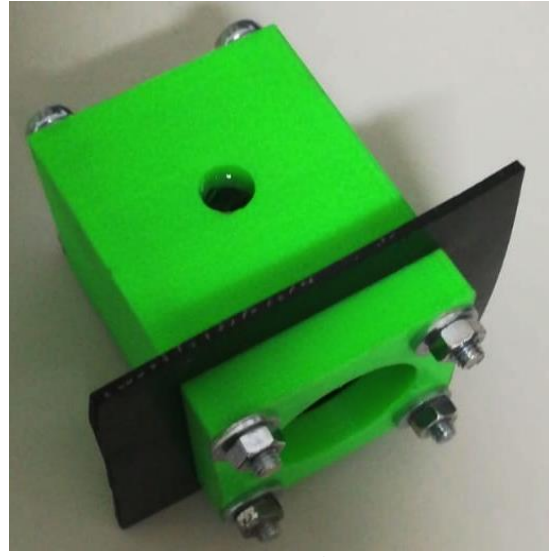

a)

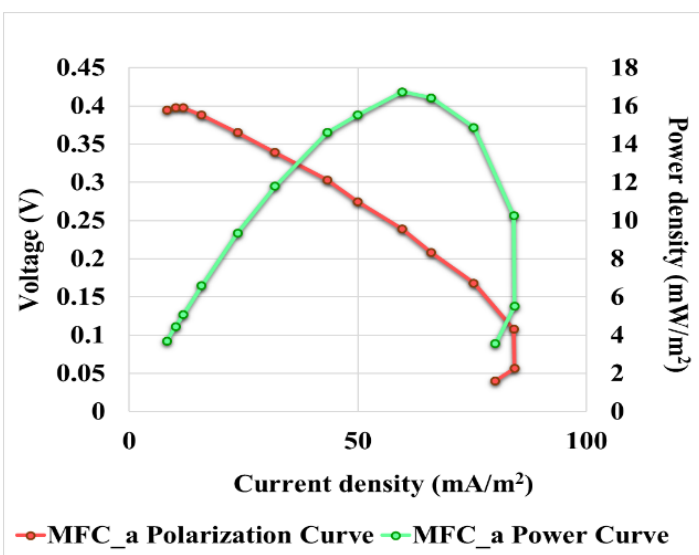

b)

Fig.8. The MFC_a (a) and the performance of the cell (b)

\subsection{Larger-scale MFCs versus Smaller-scale MFC: performance comparison}

In order to evaluate the influence of the geometric parameters of the reactors, the measured performances of the larger-scale MFCs and of the smaller-scale MFC were compared, as illustrated in Figure 9. The parameters taken into account were the ratio between anodic and cathodic surfaces, the electrodes spacing and the ratio between cell volume and anode volume. In particular, this last parameter is very important because promotes the electro-activity of microbial community at the anode while balancing steric and chemical-physical factors like, for example, the protons transport to the cathode.

It is possible to note that the MFC_a has the highest power density $\left(16.7 \mathrm{~mW} / \mathrm{m}^{2}\right.$ at $59.7 \mathrm{~mA}$ / $\mathrm{m}^{2}$ ) with respect to the multi-electrodes cells. In terms of power production, the highest values are measured for the MFC_3a $(20.8 \mu \mathrm{W}$ at $48.4 \mu \mathrm{A})$. This means that the efficiency in the energy conversion of the MFC_a is better with respect to the multi-electrodes cells because at a fixed cathodic surface it is possible to obtain more electric power. On the other 
hand, the using of 3 anodes with their three biofilms and the bigger volume of the reactor (more substrate) allow producing more electricity.

These results can be better explained by analyzing and comparing the main geometric parameters that affect the electric power production of the MFCs. These parameters are summarized in table 3 .

As suggested by Lanas et al. [3] the parameters such as the anode-brush diameter, the anode/cathode surface ratio, the anode/cell volume ratio have a great influence on the attended performances and can give suggestions in designing the scaling-up of MFCs.

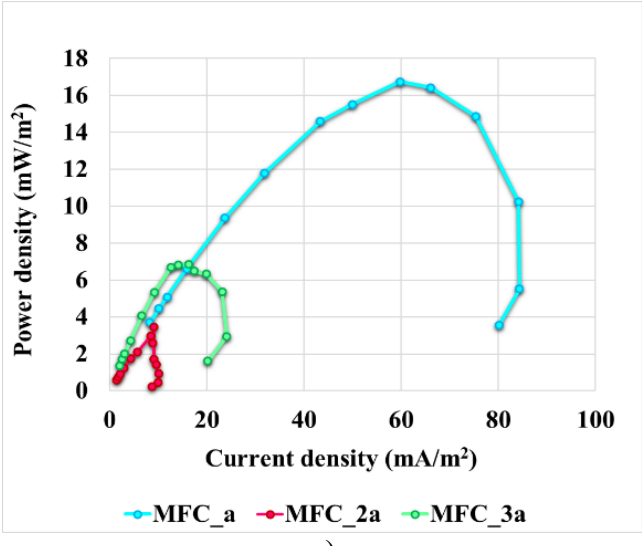

a)

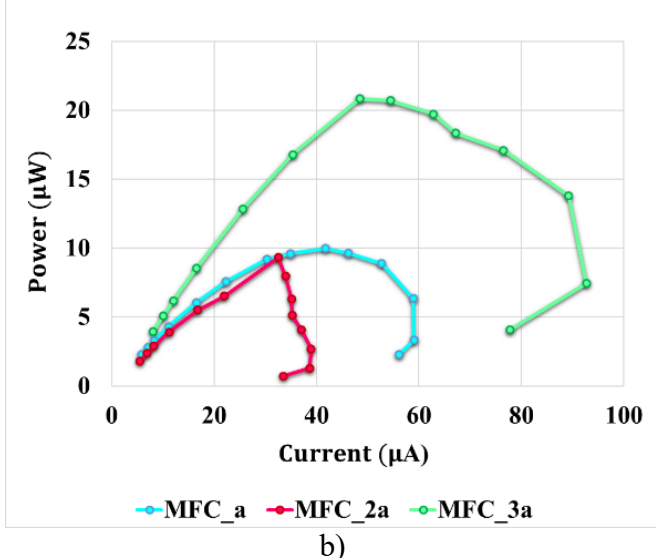

b)

Fig.9. Performance comparison of different scale MFCs in terms of power density (a) and power (b)

It can be affirmed that, the MFC_a has the most favorable geometric data unlike multielectrodes cells. Moreover, the data of the MFC_3a, even if are low, are higher of the minimum threshold that is required for overcoming or, at least, for balancing the establishment of a fermentation metabolism.

Table 3. The main geometric parameters of the MFCs that can affect the cells performances

\begin{tabular}{|l|c|c|c|c|}
\hline & Units of measure & MFC_a & MFC_2a & MFC_3a \\
\hline Approximate anodes base area & $\mathrm{cm}^{2}$ & 4.9 & 9.8 & 14.7 \\
\hline Anodes total surface area* & $\mathrm{cm}^{2}$ & 2200 & 4400 & 6600 \\
\hline Cathode surface area & $\mathrm{cm}^{2}$ & 7 & 38.5 & 38.5 \\
\hline MFC chamber volume & $\mathrm{Ml}$ & 31.8 & 346.2 & 346.2 \\
\hline $\begin{array}{l}\text { Approx. anodes base } \\
\text { area/Cathode surface area }\end{array}$ & $\mathrm{cm}^{2} / \mathrm{cm}^{2}$ & 0.7 & 0.25 & 0.38 \\
\hline $\begin{array}{l}\text { Total anodes surface } \\
\text { area/cathode surface area* }\end{array}$ & $\mathrm{cm}^{2} / \mathrm{cm}^{2}$ & 314 & 114 & 171 \\
\hline $\begin{array}{l}\text { Anodes volume/ MFC chamber } \\
\text { volume }\end{array}$ & $\mathrm{cm}^{3} / \mathrm{cm}^{3}$ & 0.38 & 0.07 & 0.10 \\
\hline
\end{tabular}

*This measure takes into account the total number of carbon fibers, their surface and porosity. 


\section{Conclusion}

In this paper the design, the development and the performance analysis of two largerscale MFCs with 2 and 3 anodes were carried out.

Results of the experiments showed that, after a longer acclimatization period, the MFC_3a reached the best performance in terms of power density $\left(13.1 \mathrm{~mW} / \mathrm{m}^{2}\right.$ at $\left.33.2 \mathrm{~mA} / \mathrm{m}^{2}\right)$.

The behavior of the multi-electrodes MFCs under different operating conditions and in a long period of measurements was also evaluated by applying 3 testing cycles: $\mathrm{C} 1, \mathrm{C} 2$ and $\mathrm{C} 3$.

These testing cycles demonstrated the ability of MFC_3a to respond with a good readiness in the electric power production under variable voltage conditions.

Moreover, in order to evaluate the influence of the geometric parameters like the ratio between anodic and cathodic surfaces, the electrodes spacing and the ratio between cell volume and anode volume, the measured performances of the larger-scale MFCs were compared to those of the smaller-scale MFC with a single anode (MFC_a).

The comparison highlighted that the MFC_a has the highest power density $\left(16.7 \mathrm{~mW} / \mathrm{m}^{2}\right.$ at $59.7 \mathrm{~mA} / \mathrm{m}^{2}$ ) with respect to the multi-electrodes cells, even if the using of 3 anodes allows producing more electricity. This trend is due to the geometric parameters that favor the smallest reactor. Results of this study pointed out that the increase of the reactor volume with multiple anodes could not represent the optimal solution towards the MFCs scaling-up. This means that the research activities will be oriented to evaluate other approaches, like modular systems connected each other in series-parallel configurations.

This research is founded by POR CAMPANIA FESR 2014/2020 - ASSE 1 - O.S. 1.2 (Project "IDRICA - Laboratorio Integrato per il monitoraggio, controllo e gestione ottimale Delle Risorse IdriChe e Ambientali” project, code B63D18000310007).

\section{References}

[1] H. Liu, S. Cheng, BE. Logan, Environ Sci Technol, 39: 5488-5493 (2005).

[2] Y. Ahn, BE. Logan, Appl Microbiol Biotechnol, 93: 2241-8 (2012).

[3] V. Lanas, Y. Ahn, BE. Logan, J Power Sources, 247: 228-234 (2014).

[4] S. Ford, M. Despeisse, J Clean Prod, 137: 1573-1587 (2016).

[5] P. Aelterman, S. Freguia, J. Keller, W. Verstraete, K. Rabaey, Appl Microbiol 78: 409-18 (2008).

[6] R. Rossi, D. Jones, J. Myung, E. Zikmund, W. Yang, YA Gallego, et al.. Water Res, 148 : $51-59$ (2019).

[7] BE. Logan, S. Cheng, V. Watson, G. Estadt, Environ Sci Technol, 41: 3341-3346 (2007).

[8] F. Flagiello, E. Gambino, RA. Nastro, C. Kuppam. H Nature Singapore Pte Ltd. Accepted.

[9] B. Cercado, N. Byrne, M. Bertrand, D. Pocaznoi, M. Rimboud, W. Achouak, et al, Bioresour Technol, 134: 276-2842 (2013).

[10] B. Cercado-Quezada, ML. Delia, A. Bergel, J Appl Electrochem, 40, 225-232 (2010).

[11] B. Logan, Nature, 454 : 943 - 944 (2008).

[12] DM. Hodgson, A. Smith, S Dahale, JP. Stratford, JV. Li, et al, Front Microbiol, 7: 699 (2016). 